\title{
The relationship between the coefficient of discharge and the scour hole depth generated due to the combined flow over weir and below gates
}

\author{
Saleh Khassaf ${ }^{1}$, Hassan Omran ${ }^{2}$ and Fadhel Abdulabbas ${ }^{3 *}$ \\ ${ }^{1}$ Department of Civil Engineering, College of Engineering, Al-Basrah University, Basrah, Iraq \\ ${ }^{2}$ Department of Building and Constructions, University of Technology, Baghdad, Iraq \\ ${ }^{3}$ Faculty of Engineering, Kufa University, Najaf, Iraq
}

\begin{abstract}
In this research, a study was conducted experimentally to investigate the scour hole dimensions downstream the combined structures which consist of weir and gate due to the effect of the coefficient of discharge $\left(\mathrm{C}_{\mathrm{d}}\right)$ due to flow above the compound weir to the flow under the gate. Fifteen models have been designed, and every model is formed from composite weir consisting of two geometric shapes with rectangular gate of constant dimensions. In this study, the experiment was conducted in a laboratory channel was constructed from blocks and concrete with length of $18 \mathrm{~m}, 1 \mathrm{~m}$ width and depth of $1 \mathrm{~m}$, where the laboratory models were installed after $7 \mathrm{~m}$ from the main gate which controlled the passage of water from the main reservoir into the flume. At the beginning, the calibration process was conducted to identify the actual discharge values that pass in the flume, and then seventy-five experiments were conducted in order to derive the formulae for investigating the non-dimensional depth $\left(\mathrm{SD} / \mathrm{d}_{50}\right)$ and non-dimensional length $\left(\mathrm{SL} / \mathrm{d}_{50}\right)$ of the scour hole due to the effect of $\left(\mathrm{C}_{\mathrm{d}}\right)$. The bed of the flume was spread with sand layer of $30 \mathrm{~cm}$ thick for a distance of $4 \mathrm{~m}$ downstream combined structure. Two samples of sand were used in the experiments with different median size of particles $\left(\mathrm{d}_{50}\right)$, the first of $0.7 \mathrm{~mm}$ and the second of 1 $\mathrm{mm}$. Using the Excel program 2017, Six polynomial relationships were derived to calculate the dimensionless scour depth $\left(\mathrm{SD} / \mathrm{d}_{50}\right)$ in terms of the coefficient of discharge $\left(\mathrm{C}_{\mathrm{d}}\right)$, where the resultant coefficients of determinations $\left(\mathrm{R}^{2}\right)$ from these relationships were high.
\end{abstract}

\section{Introduction}

Weirs and gates are the common and important structures which are used in controlling and adjusting the flow in irrigation channel. Weirs are widely used for flow measurements. One of the demerits of weirs is that they need to be cleaned of sediment and trash periodically. Sluice gates are used extensively for flow control and water measurement for long time. One disadvantage of the sluice gates is they retain the floating materials.

In order to maximize their advantages, weirs and gates can be combined together in one device, so that water could pass over the weir and below the gate simultaneously.

Fig. 1 shows this structure, this compound device creates a new hydraulic condition in compression with weir or gate, each other alone. The combined weir and gate systems can be used in minimizing sedimentations and depositions [1].

\footnotetext{
* Corresponding author: fadhil.alshitali@uokufa.edu.iq
}

The economic aspect is one of the important factors in the creation of such a project and to reduce the cost of any project, optimal running of the structure without damage in future is taken into consideration.

The non-use of concrete floor at downstream of the structure, which is designed to dissipate energy flow passing over the edge of the weir is one of the most important methods reduce cost. This alternative is less expensive and is available and ensures the lack of access scour, which leads to the occurrence of damage in the structure and thus keeps it fully within the allowable limits. 


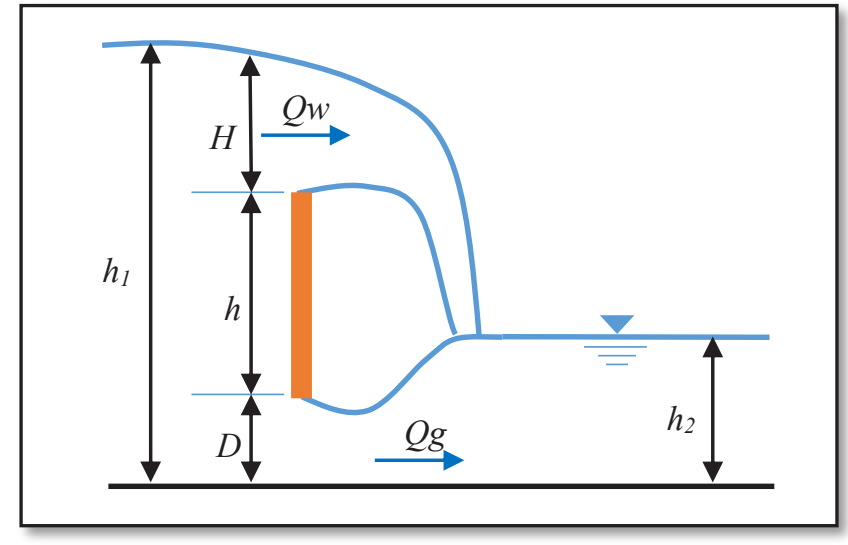

Fig. 1. Definition sketch for combined free flow over weirs and under gates.

Ahmed [2], investigated the scour characteristics downstream weirs, gates and combined structures consisting of weir and gate. The study included the measurement of maximum scour depth $\left(D_{s}\right)$ and the length $\left(\mathrm{L}_{\mathrm{s}}\right)$ of scour hole downstream these structures. Also, the effects of structure height, under sluice opening height, discharge variation and bed material size $\left(D_{50}\right)$ on the depth and length of scour hole. Two empirical relationships were obtained to estimate $\left(\mathrm{D}_{\mathrm{s}} / \mathrm{D}_{50}\right)$ and $\left(\mathrm{L}_{\mathrm{s}} / \mathrm{D}_{50}\right)$ in terms of Froude number $\left(\mathrm{Fr}_{0}\right)$, relative water surface fall $\left(\Delta \mathrm{H}_{\mathrm{w}} / \mathrm{P}\right)$, relative opening height $\left(\mathrm{h}_{0} / \Delta \mathrm{H}_{\mathrm{t}}\right)$ and relative discharge $\left(\mathrm{q}_{\mathrm{u}} / \mathrm{q}_{\mathrm{d}}\right)$ for compound gates with high correlation coefficients.

Dehghani et al. [3] studied the scour characteristics of scour hole downstream of combined free over weir and below gate experimentally. The conceptual model of flow field downstream of combine flow over the weir and under the gate indicates that there are interactions between the flows over the weir and under the gate and the scour hole cuts and fills alternatively. By increasing the Froude number, the maximum depth of scour (hs), length of scour $\left(l_{1}\right)$ and sedimentation length $\left(l_{2}\right)$ increase.

Sobeih et al. [4] investigated the scour depth downstream weir with holes. An experimental study (with 171 experiments) was carried out in a rectangular flume. The weir used in the research was perforated with different numbers of holes located at different heights (h) with respect to the height of weir (p). The arrangement of opening were included with three cases; first with no hole, second with one hole and third with three holes. The diameter of hole (d) differs from case to another and it was $0.5 \mathrm{inch}, 0.75 \mathrm{inch}$ and $1 \mathrm{inch}$ with different height (h) for each case as a percent of weir height (p) and it was $0,0.25$ and 0.5 . The research showed that the case when the ratio of height of the hole (h) to the weir height (p) equal to 0.25 , the scour depth is minimum and when the same ratio equal to 0.5 , the scour depth is the maximum value. Also, at a specific value of $(\mathrm{h} / \mathrm{p})$, when the ratio of the diameter of the hole (d) to the height of the weir (p) equal to 0.149 , the scour depth is minimum with number of holes equal to one. While, when the same ratio equal to 0.075 with three holes, also the minimum value of scour be realized.

An empirical equation was derived to estimate the scour depth depending on multi variables such as Froude number, height of holes, number and diameter of holes, weir height and the flow condition at downstream side of the weir.

\section{Laboratory models}

Fifteen models were used in the experimental work to investigate the derived formulae describing the relationships between dimensionless scour hole depth and the coefficient of discharge $\left(\mathrm{C}_{\mathrm{d}}\right)$. Laboratory experiments have been conducted by a channel, which was manufactured by the researcher and was built from blocks and concrete, and consisted of the following parts as shown in Fig. 2.

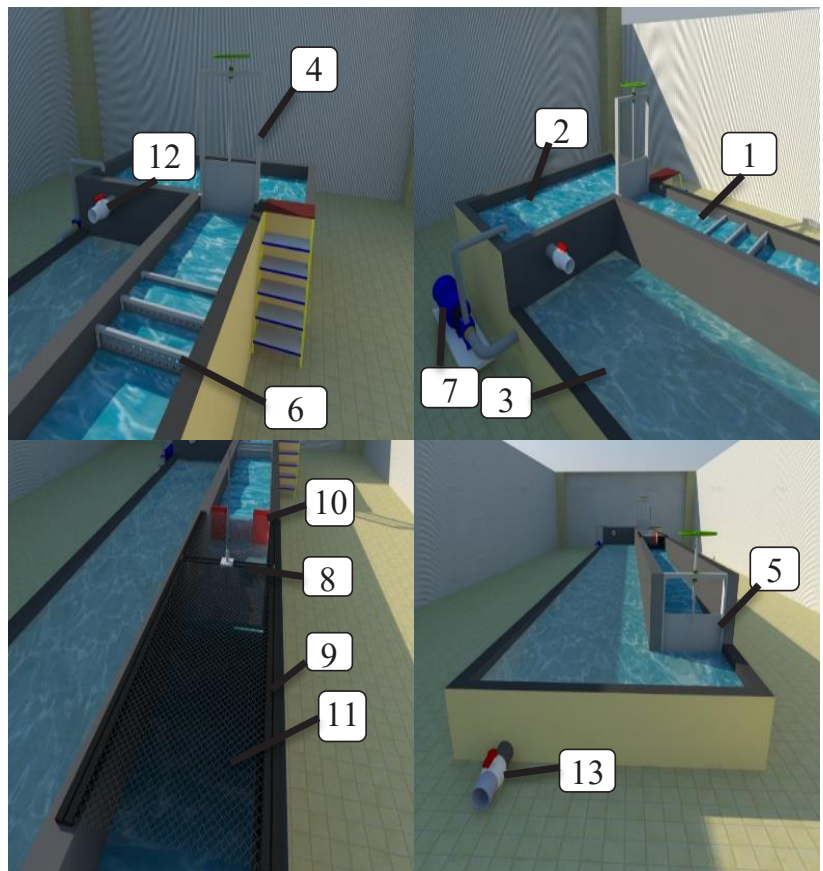

Fig. 2. The Flume Parts and Accessories: 1. The flume, 2. Head basin, 3. Lateral basin, 4. Vertical sluice head gate, 5. Vertical. sluice tail gate, 6. Stilling screens, 7. Main pump, 8. Gauge point, 9. Rails, 10. Iron frame, 11. BRC mesh, 12. Overflow valve, 13. Exhausting and cleaning valve.

A calibration process was conducted to the flume by using a standard weir, which is designed according to USBR limitations for standard sharp crested weir with $90^{\circ}$ $\mathrm{V}$ notch [5]. The laboratory models were divided into four groups with respect to compound weir shape as shown in Fig. 3: 


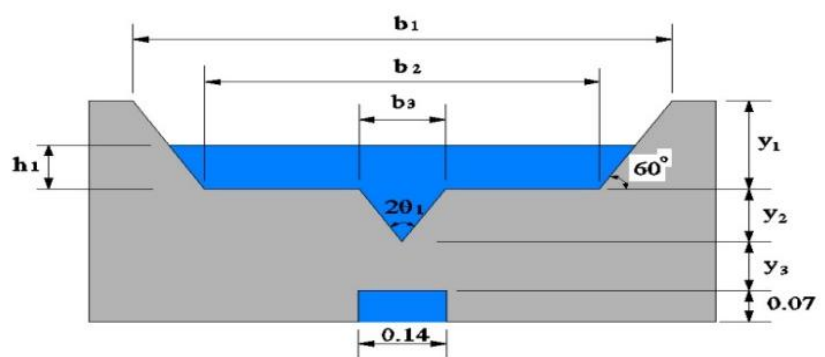

(a)

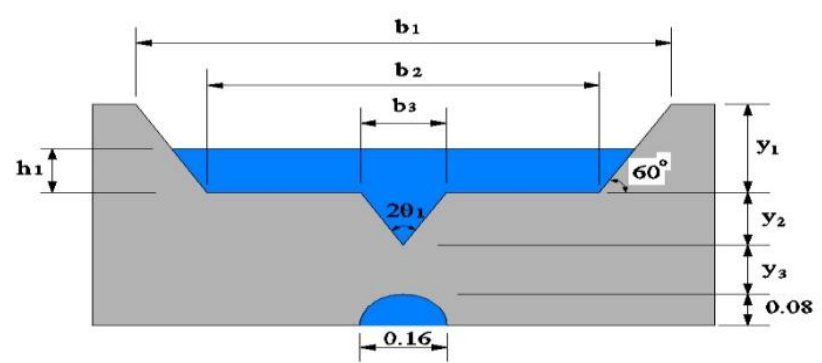

(b)

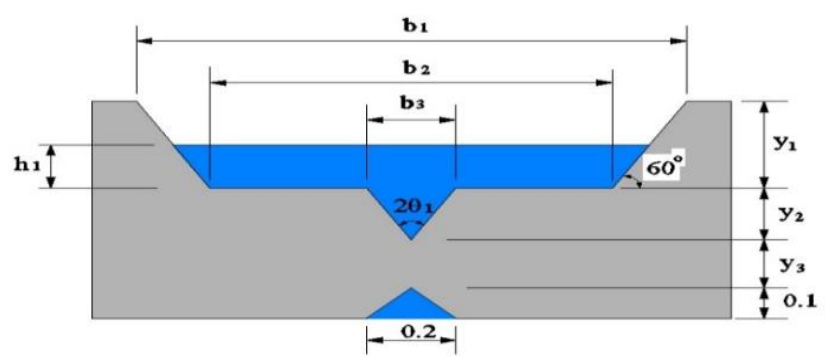

(c)

Fig. 3. General definition sketch for (a) first five models (b) Second five models (c) Third five models.

The geometrical dimensions for all tested models are listed in Table 1. It should be mentioned that the following geometric parameters are constant for all the tested models:

1) The width $(\mathrm{B})=1 \mathrm{~m}$ and the overall height $(\mathrm{L})=0.5$ $\mathrm{m}$. for all models.

2) The height of upper part of compound weir ( $\left.y_{1}\right)$ for all models $=0.2 \mathrm{~m}$.

3) The gates dimensions are same for each five models = $(0.14 \mathrm{~m}$. width $* 0.07 \mathrm{~m}$. height for rectangular gate, $0.16 \mathrm{~m}$. width $* 0.08 \mathrm{~m}$. height for semi- circular gate and $0.2 \mathrm{~m}$. width $* 0.1 \mathrm{~m}$. height for triangular gate).
Table 1. Geometric Properties for Laboratory Models.

\begin{tabular}{|c|c|c|c|c|c|c|c|c|}
\hline $\begin{array}{c}\text { Mod } \\
\text { No. }\end{array}$ & $\begin{array}{c}\mathrm{y}_{2} \\
(\mathrm{~m})\end{array}$ & $\begin{array}{c}\mathrm{y}_{3} \\
(\mathrm{~m})\end{array}$ & $\begin{array}{c}\mathrm{b}_{1} \\
(\mathrm{~m})\end{array}$ & $\begin{array}{c}\mathrm{b}_{2} \\
(\mathrm{~m})\end{array}$ & $\begin{array}{c}\mathrm{b}_{3} \\
(\mathrm{~m})\end{array}$ & $\begin{array}{c}\mathrm{D} \\
(\mathrm{m})\end{array}$ & $\Theta_{1}$ & $\Theta_{2}$ \\
\hline 1 & 0.12 & 0.11 & 0.88 & 0.19 & 0.15 & 0.14 & 60 & 30 \\
\hline 2 & 0.09 & 0.14 & 0.76 & 0.36 & 0.18 & 0.14 & 45 & 45 \\
\hline 3 & 0.08 & 0.15 & 0.61 & 0.38 & 0.2 & 0.14 & 30 & 60 \\
\hline 4 & 0.07 & 0.16 & 0.58 & 0.43 & 0.22 & 0.14 & 20 & 70 \\
\hline 5 & 0.06 & 0.17 & 0.53 & 0.46 & 0.26 & 0.14 & 10 & 80 \\
\hline 6 & 0.12 & 0.1 & 0.88 & 0.19 & 0.15 & 0.16 & 60 & 30 \\
\hline 7 & 0.09 & 0.13 & 0.76 & 0.36 & 0.18 & 0.16 & 45 & 45 \\
\hline 8 & 0.08 & 0.14 & 0.61 & 0.38 & 0.2 & 0.16 & 30 & 60 \\
\hline 9 & 0.07 & 0.15 & 0.58 & 0.43 & 0.22 & 0.16 & 20 & 70 \\
\hline 10 & 0.06 & 0.16 & 0.53 & 0.46 & 0.26 & 0.16 & 10 & 80 \\
\hline 11 & 0.12 & 0.08 & 0.88 & 0.19 & 0.15 & 0.2 & 60 & 30 \\
\hline 12 & 0.09 & 0.11 & 0.76 & 0.36 & 0.18 & 0.2 & 45 & 45 \\
\hline 13 & 0.08 & 0.12 & 0.61 & 0.38 & 0.2 & 0.2 & 30 & 60 \\
\hline 14 & 0.07 & 0.13 & 0.58 & 0.43 & 0.22 & 0.2 & 20 & 70 \\
\hline 15 & 0.06 & 0.14 & 0.53 & 0.46 & 0.26 & 0.2 & 10 & 80 \\
\hline
\end{tabular}

Each model was examined by five values of actual discharge $\left(\mathrm{Q}_{\mathrm{act}}\right)$ which are $0.037,0.031,0.026,0.011$ and $0.006 \mathrm{~m}^{3} / \mathrm{s}$.

\section{Sieve analysis for bed material samples}

In this study, sand was used as a material for the bed of flume and the samples which were selected included all the grades of sand from coarse to fine and as classified by the USCS classification [6].

To investigate the effect of sediment size as an effective parameter on the scouring process, two samples were selected to conduct the laboratory experiments with two mean diameter, the first of $1 \mathrm{~mm}$ and the second of $0.7 \mathrm{~mm}$.Sieve analysis and preparation of the quantities required was conducted by NSGF Company for production of sand and gravel filters. The results of sieve analysis for both samples mentioned above are as shown in Fig. 4 and Fig. 5.

The geometric standard deviation $\sigma_{g}$ of the sand size equal to 2.27 for the first sample and 2.62 for the second sample, which implies that the sand is of well-graded soil. The $\sigma_{g}$ is defined as: [7]

$$
\sigma_{g}=\sqrt{\frac{d_{84.1}}{d_{15.9}}}
$$




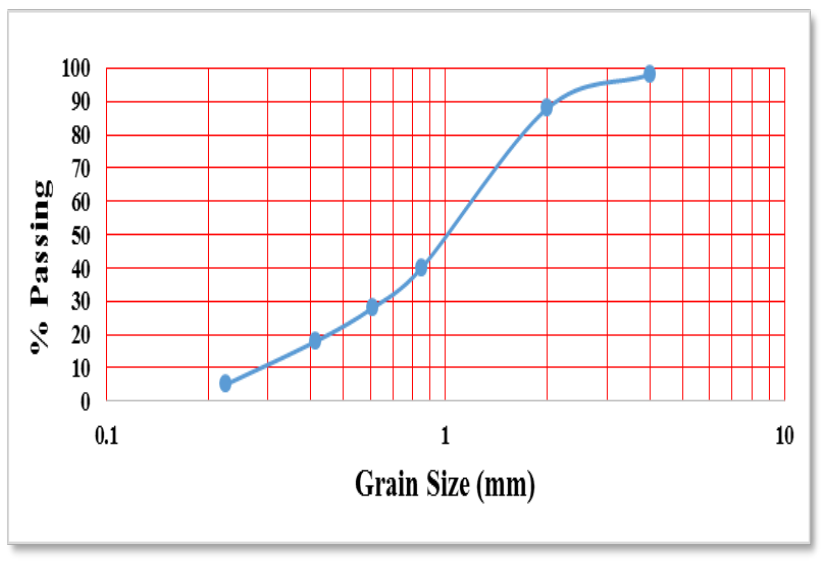

Fig. 4. Sieve analysis of bed material for the first sample $\left(d_{50}=1\right.$ $\mathrm{mm})$.

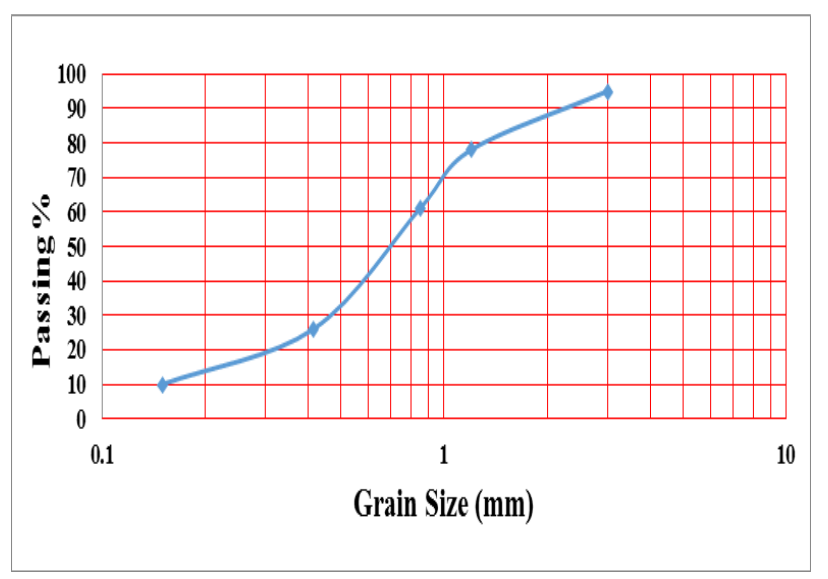

Fig. 5. Sieve analysis of bed material for the second sample $\left(\mathrm{d}_{50}\right.$ $=0.7 \mathrm{~mm}$ ).

\section{Results analysis and discussions}

\subsection{For the first five models}

As known, the increasing in flow section area (increase in $Q_{\text {act }}$ ) causes an increase in the value of the discharge coefficient and vice versa. As a result, the increase in the value of the discharge coefficient causes increase in the value of scour depth.

But whenever the theoretical discharge value increases through the combined section and the actual discharge remains constant, the value of discharge coefficient will decrease.

For the first five models, Figure (6) shows that the maximum value of $\mathrm{SD} / \mathrm{d} 50$ recorded was 390 when $\mathrm{C}_{\mathrm{d}}$ equals to 0.5009 with $\mathrm{d}_{50}$ equals to $0.7 \mathrm{~mm}$ in model no. 5 , while the minimum value of $\mathrm{SD} / \mathrm{d}_{50}$ recorded was 114 for $\mathrm{C}_{\mathrm{d}}$ value of 0.2328 in model no. 1 with $\mathrm{d}_{50}$ equals to $1 \mathrm{~mm}$ (Figure (7)).

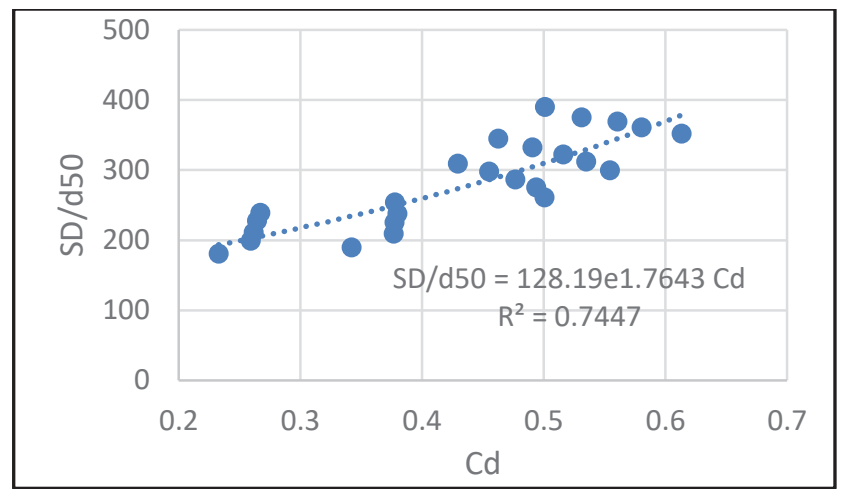

Fig. 6. The Relationship between the Non-Dimensional Scour Depth and the Coefficient of Discharge for the First Five Models $\left(\mathrm{d}_{50}=0.7 \mathrm{~mm}\right)$.

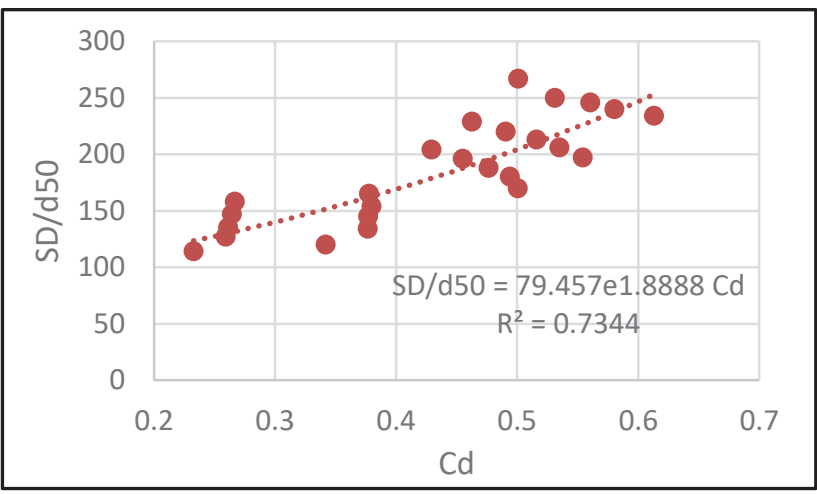

Fig. 7. The Relationship between the Non-Dimensional Scour Depth and the Coefficient of Discharge for the First Five Models $\left(\mathrm{d}_{50}=1 \mathrm{~mm}\right)$.

\subsection{For the second five models}

In the second five models, results recorded that the maximum value of $\mathrm{SD} / \mathrm{d} 50$ of 395.1 for $\mathrm{Cd}$ equals to 0.4781 with $\mathrm{d} 50$ equals to $0.7 \mathrm{~mm}$ in model no. 10 and minimum value of 140 when $\mathrm{Cd}$ equals to 0.2215 with d50 equals to $1 \mathrm{~mm}$ in model no. 6 as shown in Figures (8) and (9).

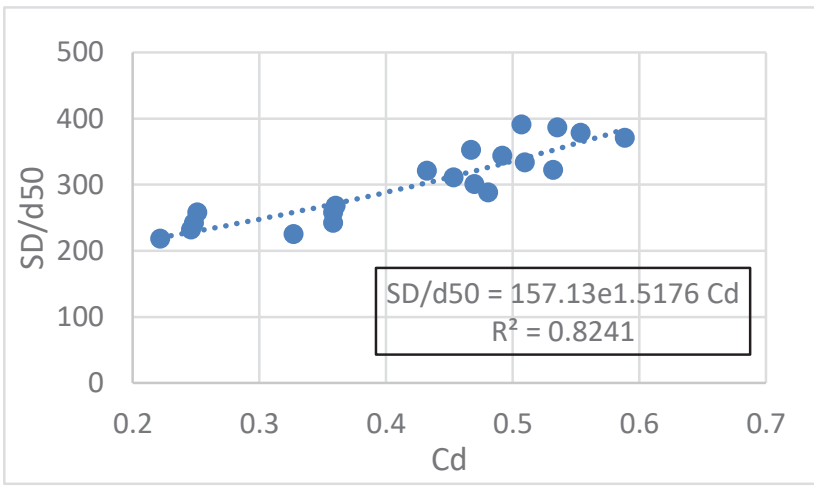

Fig. 8. The Relationship between the Non-Dimensional Scour Depth and the Coefficient of Discharge for the Second Five Models $\left(\mathrm{d}_{50}=0.7 \mathrm{~mm}\right)$. 


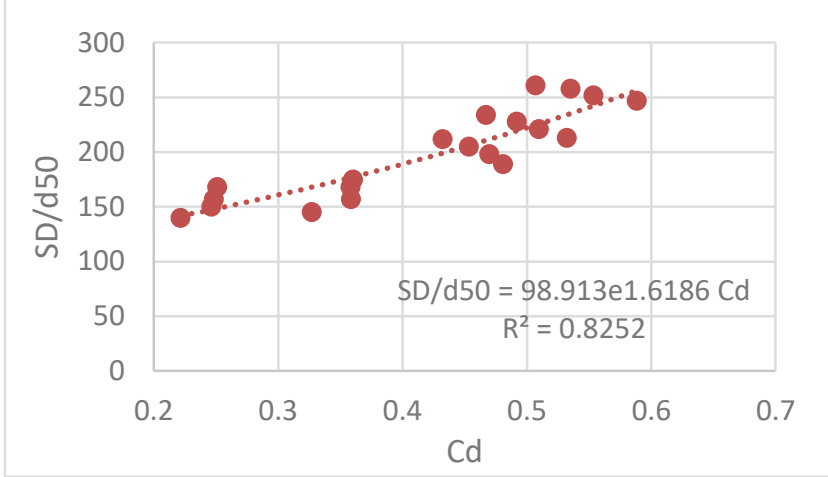

Fig. 9. The Relationship between the Non-Dimensional Scour Depth and the Coefficient of Discharge for the Second Five Models $\left(\mathrm{d}_{50}=1 \mathrm{~mm}\right)$.

\subsection{For the third five models}

The third five models, as shown in Figures (10) and (11), results recorded the maximum value of $\mathrm{SD} / \mathrm{d} 50$ of 379.4 for Cd equals to 0.5217 with $\mathrm{d} 50$ equal to $0.7 \mathrm{~mm}$ in model no. 15 and minimum value of 107 when $\mathrm{Cd}$ equals to 0.2377 with $\mathrm{d} 50$ equals to $1 \mathrm{~mm}$ in model no. 11 .

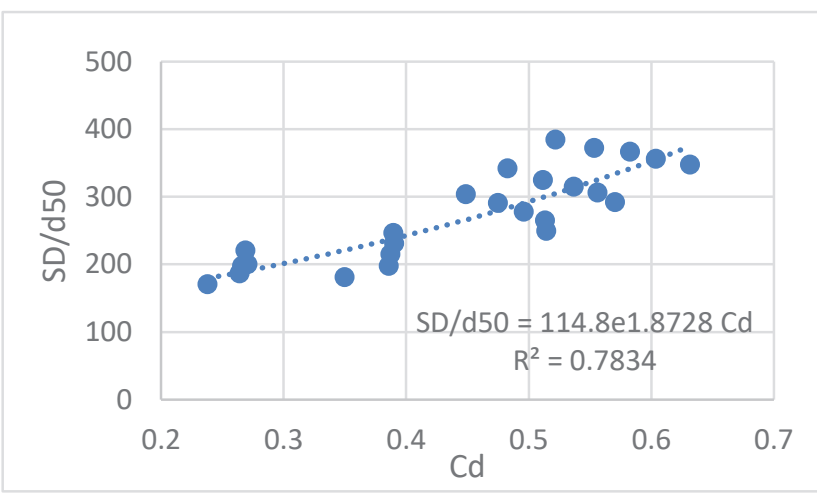

Fig. 10. The Relationship between the Non-Dimensional Scour Depth and the Coefficient of Discharge for the Third Five Models $\left(\mathrm{d}_{50}=0.7 \mathrm{~mm}\right)$.

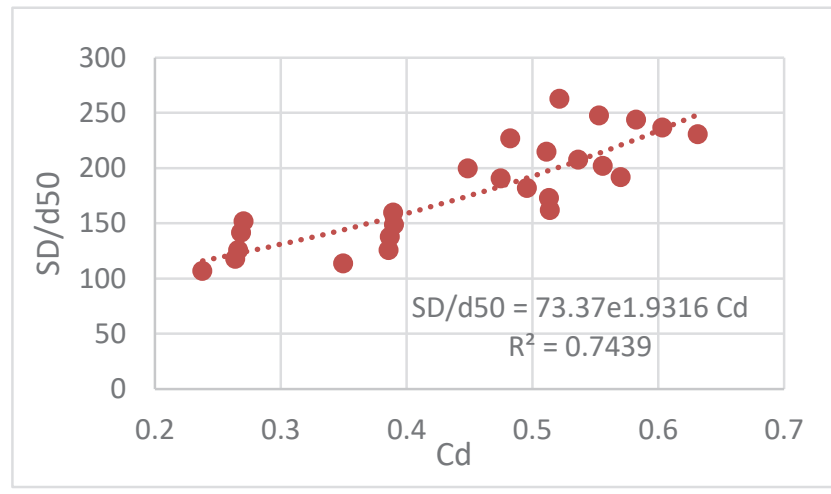

Fig. 11. The Relationship between the Non-Dimensional Scour Depth and the Coefficient of Discharge for the Third Five Models $\left(\mathrm{d}_{50}=1 \mathrm{~mm}\right)$.

\section{Scour hole form}

Surfer-ver. 11 program was used to draw a threedimensional profile to the sandy bed of the flume after scour process is complete. The following figures from (12) to (14) represent the form of scour hole downstream of some combined models, which were used in the laboratory experiments.

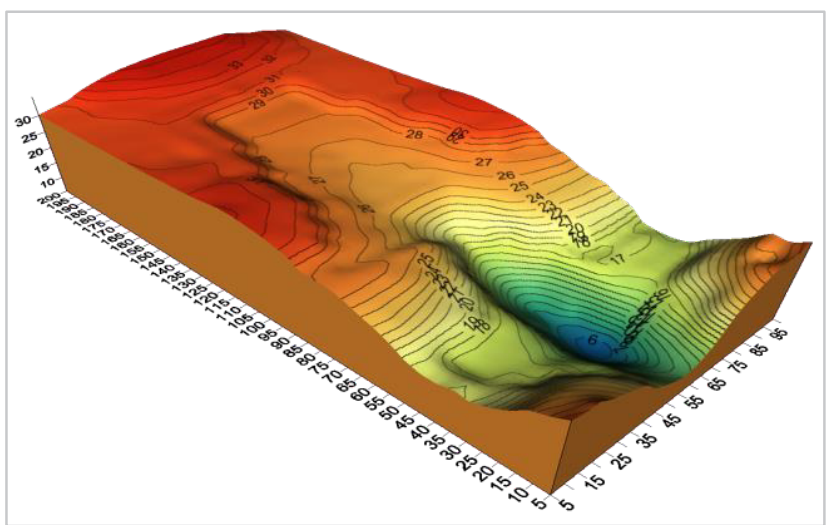

Fig. 12. 3D- Scour Profile for Model $\# 1$ for $Q=0.037 \mathrm{~m}^{3} / \mathrm{s}$ and $\mathrm{d}_{50}=0.7 \mathrm{~mm}$.

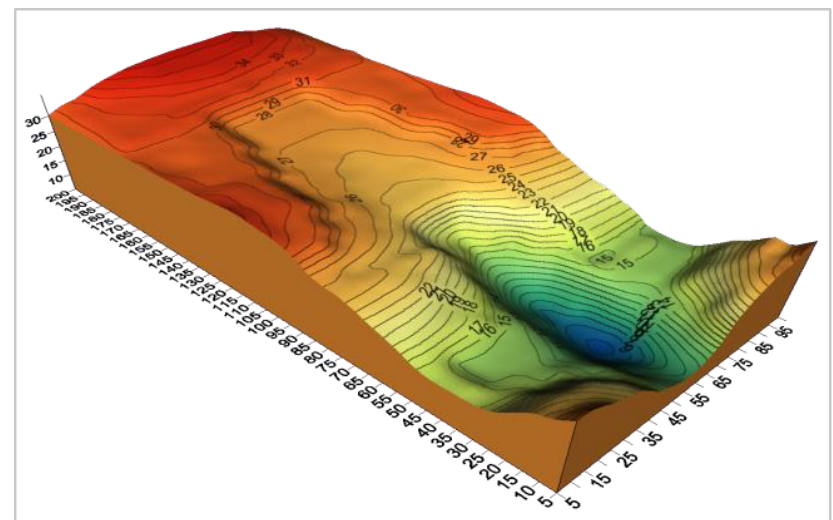

Fig. 13. 3D- Scour Profile for Model $\# 6$ for $\mathrm{Q}=0.037 \mathrm{~m}^{3} / \mathrm{s}$ and $\mathrm{d}_{50}=0.7 \mathrm{~mm}$.

Fig. 14. 3D- Scour Profile for Model $\# 11$ for $Q=0.037 \mathrm{~m}^{3} / \mathrm{s}$ and

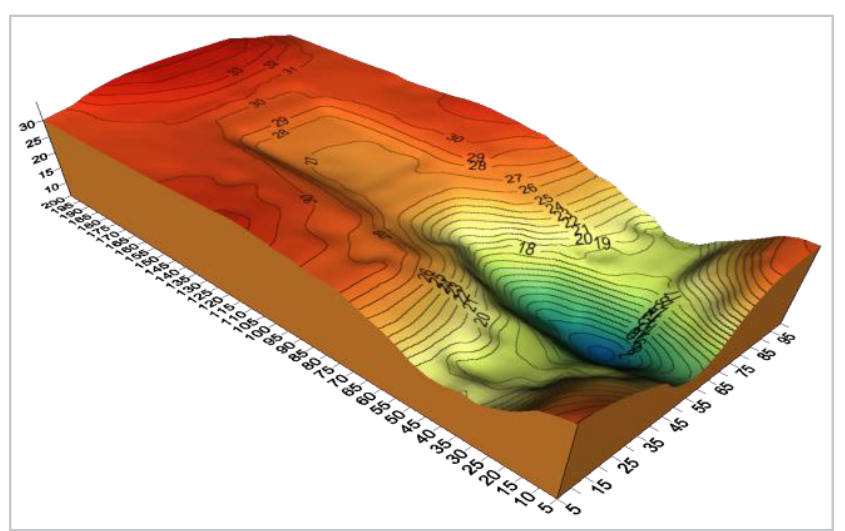

$\mathrm{d}_{50}=0.7 \mathrm{~mm}$. 


\section{Conclusions}

In this study, the following conclusions are made from $\mathrm{SD} / \mathrm{d}_{50}$ and $\mathrm{SL} / \mathrm{d}_{50}$ vs. $\mathrm{Q}_{\mathrm{r}}$ for various values of actual discharges $\mathrm{Q}_{\text {act }}$ and $\mathrm{d}_{50}$ :

1) The results show that the maximum values of $S D / d_{50}$ for the fifteen models was recorded generally in the second five models and especially in model no. 10 in which the compound weir consisted of trapezoidal upper part and rectangular lower part with a gate semicircular in shape. The maximum scour depth was recorded as $27.7 \mathrm{~cm}$ in sandy bed with $\mathrm{d}_{50}$ of $0.7 \mathrm{~mm}$ and $30 \mathrm{~cm}$ thickness. In addition, the maximum scour depth was recorded against actual discharge of 0.037 $\mathrm{m}^{3} / \mathrm{s}$ and relative discharge. While the minimum value of $\mathrm{SD} / \mathrm{d}_{50}$ was recorded in model no. 11 , in which the gate is triangular. The minimum value was $10.7 \mathrm{~cm}$ in sandy bed with $\mathrm{d}_{50}$ of $1 \mathrm{~mm}$ and $30 \mathrm{~cm}$ thickness.

2) Both values of SD increase with increase in the values of actual discharge passing through the flume and relative discharge between compound weirs to the flow under the gate.

3) The most controlled hydraulic factor in the value depth of the scour hole is Froude number in terms of the mean size of bed material $\left(\mathrm{d}_{50}\right)$ where always the relationship is positive, that is, when the value of Froude number increases each of SD and SL increased for all models in all groups.

4) The size of the depositions changes with the depth and length of the scour hole where whenever the hole depth increases as a result of the free fall of water from the edge of the compound weir, the deposition of sediments was more, while the flow through the gate is helping to pay these sediments away and make the form seem more flat.

5) Whenever the weir width increases, the scour hole generated becomes more flat even with the increase in the value of discharge passing through it and this is evident by the results of the third and fourth five models.

\section{References}

1. Dehghani, A. A., Bashiri, H., Dehghani, N., River Flow - Dittrich, Koll, Aberle \& Geisenhainer, (2010).

2. Ahmed, A. A., University of Mousel, (2007).

3. Dehghani, A.A., Bashiri, H., Shahmirzadi, M.E.M., WSEAS Press, (2010).
4. Sobeih M. F., Helal, E. Y., Nassralla, T. H., Abdelaziz, A. A., International Journal of Civil and Structural Engineering, Volume 3, No. 1 (2012).

5. USBR, U. S. Department of the Interior, Bureau of Reclamation, Revised Reprinted of Third Edition, (2001)

6. Murthy, V. N. S., Marcel Dekker, Inc., First Edition, (2002).

7. Chanson, H, Butter Worth Heineman, Second Edition, (2004). 